\title{
E-prescription in Poland - A PReliminary Report
}

\author{
BARBARA GRABOWSKA \\ Department of Promotion of Health, Faculty of Health Sciences, Wrocław \\ Medical University ul. Barta 5, 51-618 Wrocław, Poland \\ e-mail address: barbara.grabowska@umed.wroc.pl \\ ORCID: 0000-0001-7466-1280
}

\author{
Mariola SEŃ \\ Wrocław Medical University \\ ul. Barta 5, 51-618 Wrocław, Poland \\ e-mail address: mariola.sen@umed.wroc.pl \\ ORCID: 0000-0002-6790-654X
}

Department of Disorders of the Nervous System, Faculty of Health Sciences,

\author{
IWONA KLISOWSKA \\ Department of Disorders of the Nervous System, Faculty of Health Sciences, \\ Wrocław Medical University \\ ul. Barta 5, 51-618 Wrocław, Poland \\ e-mail address: iwona.klisowska@umed.wroc.pl \\ ORCID: 0000-0001-6829-3880
}

\begin{abstract}
Aim. Aim of the paper: to introduce the subject of e-prescription in Poland. E-prescription is a digital version of the previously used standard paper prescription. In Poland, professional arrangements were made, thanks to which it became possible to promote e-prescriptions in pharmacies and doctors' surgeries throughout the country.

Methods. The authors analyse how e-prescription is introduced in Poland. We applied comparative analysis (of eprescining in the European Union countries), literature review (what are legal and technical constraints) and case study (how it was introduced in Poland).

We showed the implementation of the e-Health (P1) system in Poland and described the use of the free application of the Ministry of Health. We presented preparations for the implementation of digital health services by the Center for Health Information Systems (CSIOZ).

Results and conclusion. For years in Poland, handwritten prescriptions used to be the preferred method of communication for doctors when making decisions about therapy with medications and for pharmacists to distribute them. Nonetheless, over the last decade, interest in the subject of e-prescription, alongside other e-health solutions for processing health-related data, has increased. E-prescription is filled on the basis of a four-digit code, which we receive by text message sent to a given phone number or by email to an indicated address. Alternatively, there is a possibility to obtain an information printout, depending
\end{abstract}


on the configuration of our Patient Account. An important change introduced is that we do not have to physically carry the printed prescription with us anymore. E-prescription provides benefits for doctors, patients and pharmacists, such as: convenience, time saving, greater safety of the therapy, less risk of error, less bureaucracy. The main objectives of the e-prescribing system involve facilitation of the process of prescriptions delivery, reduction of errors, time optimisation for doctors and pharmacists and eliminating the problem of illegible and fake prescriptions, which have so far been a common occurrence.

Cognitive value. This article shows the process of introducing E-prescription in Poland.

Keywords: e-prescription, electronic prescription, e-health

\section{INTRODUCTION}

ePrescription is a central IT system made available within the framework of the project entitled "Electronic Platform for the Collection, Analysis and Sharing of Digital Medical Records" - (the P1 System).

From the end of May 2018 to January 2020, more than 63 million prescriptions were issued. Over 60,000 physicians and pharmacists have received professional training. After making professional arrangements, it was possible to make ePrescriptions common in pharmacies and doctor's offices in the entire country (CSIOZ project, 2017-2020).

The main aims of the sPrescription system are to facilitate the process of filling prescriptions, reduce the number of errors, optimise the time of doctors and pharmacists and eliminate the problem of illegible and fake prescriptions that occured very often until now. ePrescriptions are a digital version of standard prescriptions issued on paper.

\section{Aim OF THE PAPER}

The aim of the paper is to introduce the topic of ePrescriptions in Poland. For years, handwritten prescriptions were the preferred method of communication in Poland - for physicians making decisions concerning pharmacological treatment and pharmacists dispensing medications. In the last decade, however, there has been an increase in the interest in ePrescriptions, among other eHealth solutions for the processing of health-related data (Samadbeik, Ahmadi, \& Garavand, 2017).

Currently, a growing number of Polish people can see the benefits of using online sources, with $75 \%$ of respondents stating that they have used the Internet for purposes associated with health care in the last 12 months, which indicates that ePrescriptions will be positively accepted and adopted in Poland (Borek et al. 2017).

Electronic prescriptions appeared in Polish pharmacies already in January 2019. From that moment on, they could be filled at any pharmacy in the country. On 8 January 2020, the obligation to issue prescriptions in the electronic form came into force. 
In May 2018, the Ministry of Health and the Center for Health Care Information Systems (Centrum Systemów Informacyjnych Ochrony Zdrowia, CSIOZ) began intensive preparations for the implementation of digital health services. ePrescriptions were the first service presented to patients, doctors and pharmacists. The first phase, which was completed in December 2018, involved connecting all pharmacies to the eHealth system (P1). Thanks to the training provided to pharmacists, it was possible to implement the first step in the popularisation of ePrescriptions in Poland (eHealth Centre, 2020).

The next stage of introducing ePrescriptions consisted in the preparation of four draft acts on eHealth, which were adopted in the years 2018-2019. Preparations for the implementation of ePrescriptions also involved training for medical specialists, attended by over 60,000 people from all over Poland. They were carried out in cooperation with professional self-governments and with the support of the National Health Fund and the Social Insurance Fund. The CSIOZ trainers showed the participants how to connect to the eHealth system (P1) and issue ePrescriptions in the free application of the Ministry of Health, gabinet.gov.pl. They also presented changes that accompanied the introduction of the eHealth act. The Ministry of Health also published videos containing instructions on how to connect to the eHealth system (P1) and issue ePrescriptions at gabinet.gov.pl. Meanwhile, in cooperation with the Supreme Chamber of Physicians, each recipient of Gazeta Lekarska was provided with "Przewodnik po e-zdrowiu od A do Z" ("The end-to-end guide to eHealth") (eHealth Centre 2020).

\section{WHAT ARE EPRESCRIPTIONS?}

ePrescriptions are electronic documents designed to replace the traditional paper prescriptions. ePrescriptions are filled on the basis of a four-digit code received in a text message sent to a given phone number or in an email sent to the provided address. Alternatively, it is also possible to obtain a printout containing the information, depending on the way our Patient Account has been configured (pacjent.gov.pl, 2020). The feature is quite useful as not every person owns a cell phone, which particularly applies to the elderly. Whenever we go to a pharmacy to fill a prescription, we must provide the 4-digit code received via SMS and our PESEL (Personal Identification Number). We can also buy medication for another person if we know their 4-digit code and PESEL. It is very helpful in the case of patients who are unable to go to the pharmacy on their own and have to ask their family members or other loved ones to help them fill their prescriptions. The fact that we no longer have to carry a printed prescription and only need a text message with adequate information is a very important change. When filling an ePerscription at a pharmacy, it is crucial that we know our PESEL, or that of the person whose ePrescription we are filling. The code is always provided in the text message.

Advantages of ePrescription are as follows: convenience, the possibility to save time, increased safety of treatment. The prescription is also always legible - there is 
no risk that we will receive a wrong medication. But ePrescriptions are also much more than traditional prescriptions. We no longer have to ask for a copy if more medications have been prescribed and do not lose the reimbursement - which is essential in the case of some expensive medications. The fact that the ePrescription cannot be lost, as it is saved in our Patient Account, constitutes another important advantage thereof. This is an important issue because until now, patients would frequently lose their prescriptions. We should remember that when using the Individual Patient Account (Indywidualne Konto Pacjenta, IKP), we can check the dosing of the medication at any time, we will find the information on the prescribed dosing on our ePrescription. It is important to know that we will receive another ePrescription without having to visit to the doctor's office again (in the case of a chronic disease, having agreed upon it with the physician). We can also check the dosing prescribed to our children under the age of 18 .

ePrescriptions are quite beneficial for many people. They enable physicians to control the treatment process, establish better communication, and they reduce the amount of paperwork as well as the waiting time for the visit, providing more time in general. They enable patients to save time, they reduce the risk of an error, increase availability and are convenient. In the case of pharmacists, they enable faster dispensing of medications, increased safety and save time (eZdrowie, 2020).

It is worth noting that if a person eligible for an ePrescription does not have access to the Internet or the office system during a home visit, a paper prescription can be issued as well.

According to a survey conducted within the framework of the eHealth project, respondents see numerous benefits of an IT system that gathers information on all prescribed medications used by a patient. They believe that the main benefit of ePrescreptions is increased safety stemming from the fact that the physician and the patient can be informed that a prescribed medication cannot be used with other drugs taken by the patient as well as the possibility of receiving further prescriptions without the need to visit the doctor's office again, or the possibility of printing out the current list of medications taken by the patient. More than half of the respondents believe that the information on the availability of a medication in nearby pharmacies should be provided at each pharmacy. Patients' awareness is changing and as many as half of them positively evaluate the solution in which medications are delivered directly to the patient's home after being ordered from an online pharmacy (Borek et al., 2017).

\section{IMPLEMENTATION OF THE EPRESCRIPTION IN OTHER COUNTRIES}

Analysing the implementation of prescriptions in other countries, pharmacists working in England indicated the problem of having to incur financial costs due to the use of new technologies, in order to ensure smooth operation of the system. They emphasise that the system was received positively by pharmacies, although its use by general practitioners (GPs) is slower than expected. Almost all pharmacies in the UK can handle ePrescriptions, but their share in the total number of 
ePrescriptions issued is only 56\% at the moment (September 2017), i.e. 23 million out of 41 million prescriptions. The rest are traditional, paper prescriptions. A specific feature of the system in England is pharmacy "nomination" by the patient. It means that all ePrescriptions will be sent only to the selected pharmacy. Transposing the experiences from England to the Polish reality, the model of nominating a single pharmacy would certainly be controversial in the conditions of constant competition between Internet pharmacies and individual pharmacies. The Polish system, however, like the Estonian one, does not provide for such a solution and patients are can fill their prescriptions at any pharmacy.

Looking at the use of ePrescription in Estonia, it has been very well received by doctors, pharmacists and patients alike. In this country, paper prescriptions have been virtually eliminated in pharmacies. Importantly, just like in Poland, the patient does not have to select one pharmacy, and can visit any pharmacy they like. In Estonia, pharmacies located in supermarkets and other popular locations are in a winning position, due to the fact that patients no longer need to go to the clinic to renew their prescription when they are continuing their treatment. In connection with the electronic prescriptions, pharmacists from Estonia consider the lack of access to medical records, which makes it difficult to provide proper advice, to be a disadvantage. Another issue is the lack of access to prescription history, i.e. to see whether it has been filled or has expired (Owczarek \& Soroko, 2020).

In the USA, ePrescribing is defined as writing, sending, and filling of prescriptions electronically, as well as replacing paper and fax prescriptions. The use of ePrescribing has enabled American physicians to electronically send information on patients' prescriptions to computers at pharmacies. This process has reduced errors associated with prescribing and taking medications, and resulted in fewer calls to physicians from pharmacists wanting to clarify ambiguities. Sending and receiving of prescriptions via electronic means has improved workflow at clinics, as well as increased the satisfaction and compliance of American patients (Porterfield, Engelbert, \& Coustasse, 2014; Thomas et al., 2012). The implementation of ePrescriptions in the USA made it possible to increase safety by reducing the rate of erroneous prescriptions, which dropped from 42.5 to 6.6 per 100 ePrescriptions within a year. It also resulted a $10 \%$ improvement in the purchasing of medications in the years 2008-2010, compared to paper prescriptions. The country has also seen an improvement in the productivity of physicians, due the reduced amount of work related to completing medical documentation and cooperating with pharmacies as well as issuing prescriptions for medications taken regularly.

\section{SUMMARY}

Benefits brought to physicians, patients, and pharmacists by ePrescriptions include convenience, the possibility to save time, increased safety of treatment, reduced risk of errors, and a reduced amount of paperwork. As it is in the case of any new technology, a number of potential barriers or challenges to the imple- 
mentation of ePrescriptions have also been identified. The most commonly listed ones include the cost of system implementation, potential system errors, and data sharing issues (Gagnon, Nsangou, \& Pavne-Gagnon, 2014; Mohsin-Shaikh, 2019).

It should be emphasised that the very specific time that we are currently in, i.e. the pandemic in Poland, demonstrated that ePrescriptions were positively received and accepted by patients, doctors and pharmacists who noticed that this modern solution has many advantages. ePrescriptions have also become very important and useful at a time when standard medical visits were not possible, which is why numerous ePrescriptions have been issued during eVisits.

\section{REFERENCES}

[1] P1 CSIOZ project 2017-2020. Retrieved January 20, 2020, from https://ezdrowie.gov. $\mathrm{pl} /$.

[2] Samadbeik,M.,Ahmadi,M.,Sadoughi,F., \&Garavand, A. (2017). ACopmarativeReview of Electronic Prescription Systems: Lessons Learned from Developed Countries [published correction appears]. J Res Pharm Pract., 6(2), 1-3. doi:10.4103/2279-042X.200993.

[3] Borek, E., Greser, J., Kilijanek-Cieślik, A., Perendyk, T., Pruszko, A., Sitek, A., \& Wojtaszczyk, K. (2017). e-Zdrowie. Czego oczekują pacjenci. Warszawa: Fundacja My pacjenci.

[4] eHealth Centre, CSIOZ, Retrieved January 20, 2020, from https://csioz.gov.pl/ezdrowiepatient.gov.pl. Retrieved January 20,2020, from https:// pacjent.gov.pl/.

[5] Ezdrowie.gov.pl. Retrevied January 22, 2020, from https://ezdrowie.gov.pl/portal/ home/dla-podmiotow-leczniczych/e-recepta.

[6] Owczarek, B., \& Soroko, A. (2020). Wdrożenie e-recepty doświadczenia z UK i Estonii. Retrevied January 22, 2020, from,https://www.gdziepolek.pl/blog/wdrozenie-erecepty-doswiadczenia-z-uk-i-estonii.

[7] Porterfield, A., Engelbert, K., \& Coustasse, A. (2014). Electronic prescribing: improving the efficiency and accuracy of prescribing in the ambulatory care setting. Retrieved January 20,2020 from https://www.ncbi.nlm.nih.gov/pmc/articles/PMC3995494/.

[8] Thomas, C., Kim, M., McDonald, A., Kreiner, P., Kelleher, S., Blackman, M. et al. (2012). Prescribers' Expectations and Barriers to Electronic Prescribing of Controlled Substances. Journal of the American Med. Infor. Assoc., 19(3), 375-381.

[9] Gagnon, M-P., Nsangou, E-R., Payne-Gagnon, J., Grenier, S., \& Sicotte, C. (2014). Barriers and facilitators to implementing electronic prescription: a systematic review of user groups' perceptions. Journal of the American Medical Informatics Association, 21(3), 535-541.

[10] Mohsin-Shaikh, S., Furniss, D., Blandford, A., McLeod, M., Ma, T., Beykloo, M., \& Frankilin, B. (2019). The impact of electronic prescribing systems on healthcare professionals' working practices in the hospital setting: a systematic review and narrative synthesis. Retrieved January 20, 2020, from https:/ / bmchealthservres.biomedcentral. com/articles/10.1186/s12913-019-4554-7. 